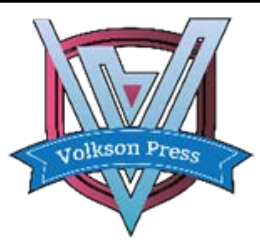

Contents List available at Volkson Press

Economics, Business and Management

(EBMan)

DOI : http://doi.org/10.26480/wsebm.01.2017.24.25

\title{
ANALYSIS ON FINANCIAL MANAGEMENT CAPABILITY OF CONTEMPORARY UNDERGRADUATES IN CHINA: TAKING BEIJING AS AN EXAMPLE
}

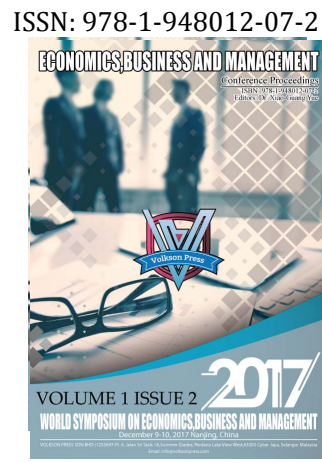

\author{
Chen Yidan \\ North China Electric Power University Beinong Road NO.2, Huilongguan Town, Changping District, Beijing, China. \\ *Corresponding Author Email: cccllemon@163.com
}

This is an open access article distributed under the Creative Commons Attribution License, which permits unrestricted use, distribution, and reproduction in any medium, provided the original work is properly cited.

\section{ARTICLE DETAILS}

\section{ARTICLE HISTORY}

Received 27th December 2017

Accepted 29th December 2017

Available online 29th December 2017

\section{KEYWORDS:}

Undergraduates, condition of consumption, financial incomes and expenses, financial management.

\section{ABSTRACT}

As an important part of social consumers, Undergraduates' financial management capability affects not only the quality of their personal life, but also the operation of social economy. Taking universities in Beijing of China as an example, this paper applies structural analysis and breakeven analysis to study the factors impacting the financial incomes and expenses of undergraduates, and puts forward reasonable suggestions on how to improve financial management capability of contemporary undergraduates in China.

\section{INTRODUCTION}

Since the enrollment expansion of Chinese colleges in 1999, the number of undergraduates has been rising continuously, and undergraduates have become increasingly important in social consumer group [1]. With the constant development of market economy in China, the financial condition of undergraduates has gained increasing social attention. University is a transitional period from school to society, and the training of financial management awareness during this period will be of crucial significance to the financial management capability of undergraduates in the future [2]. In this paper, by data analysis and breakeven analysis, a further study is made on financial management capability of contemporary undergraduates and corresponding measures are presented so as to enhance the financial management capability and life quality of contemporary undergraduates in China.

\section{DATA ANALYSIS}

\subsection{Structural analysis}

In accordance with intensive level of universities in different areas of Beijing, random sampling and questionnaire is conducted. The number of effective questionnaires is 525, where males account for 53.33\% and females $46.67 \%$ with a basically balanced proportion between males and females. Besides, proportions of freshmen, sophomores, juniors and seniors are roughly between $20 \%$ and $25 \%$ and basically balanced. Impacts of individual difference on questionnaire data can be eliminated by and large.

Financial management activity includes two aspects, incomes and expenses. Since undergraduates neither fully step into the society nor have an independent capacity to make profits and their income condition is relatively simple, attention will be paid to analysis for their consumption behavior. Results of sample data analysis are as follows.

By data statistics, monthly living costs of $44 \%$ of undergraduates are between 1000 and 1500 Yuan; 20\% are under 1000 Yuan; 18.67\% are between 1500 and 2000 Yuan; 16\% are above 2000 Yuan. By means of weighted average, monthly average consumer spending of undergraduates in Beijing is about 1500 Yuan.

With respect to source of living costs, as we expect, more than $90 \%$ of undergraduates depend on their parents' help. Only a few undergraduates are able to support themselves and gain their living costs by off-campus part-time job or scholarship and grants.

During investigation for consumed objects, consumed objects are divided into seven types, diet, clothes, articles of daily use, school things, entertainment, association and other expenses. Those seven types are sequenced by respondents in accordance with importance. Weighted average is used to calculate data results; namely scores for option $=(\Sigma$ frequency $\times$ weight)/people/time for filling in this subject. The calculation results show diet expenses are 6.71 scores, which are the highest; expenses for clothes and articles of daily use take second place with about 3.7 scores; and the remaining items are about 2.4 scores. It can be learned from data that, limited to income condition, consumption expenses of undergraduates are basically used to maintain necessity of life and high-end consumption is less.

With respect to consumption criteria, about $50 \%$ think practicability and price are top factors to be considered while others regard brand and appearance as main consumption criteria. Due to immature consumption concept, consumer psychology of keeping up with the Joneses and following others blindly is common among undergraduates. Shopping criteria for brand and appearance indirectly reflect this phenomenon.

The investigation shows a large number of undergraduates are "moonlight clan" and make ends meet on a monthly basis. Only about 20\% have a surplus at the end of month. The remaining $25 \%$ cannot make ends meet on a monthly basis. By cross-over analysis, there is found to be a positive correlation between overspending and amount of living costs; namely, the more the monthly living expenses are, the severer the overspending is. It is easy to understand this circumstance. The more the living expenses are, the freer the consumption behavior is. As a result, irrational consumption behavior is more apt to occur, causing a failure to make ends meet.

\subsection{Break-even analysis}


Break-even analysis is often used to assess the profitability of enterprises and is also applicable to individual financial behavior analysis. Break-even mentioned in this paper refers to a balance between incomes and expenses of personal living costs without overspending or surplus.

Suppose monthly income of undergraduates is fixed as 1500 Yuan, living expenses are divided into fixed expenses and variable expenses. Fixed expenses refer to spending required to maintain a daily life while variable expenses refer to those related to enhancement of life quality. According to investigation results and empirical data, when daily fixed expenses of undergraduates are about 20 Yuan, monthly fixed expenses are 600 Yuan, monthly variable expenses are 900 Yuan and variable expenses are 1.5 times of fixed expenses. It can be learned from the preceding data that expenses of contemporary undergraduates in enhancement of life quality are much higher than those in basic food and clothing. This is a common consumption phenomenon among contemporary Chinese residents and also a result of continuous development of Chinese economy.

Variable expense is further divided to a large amount, a medium amount and a small amount. A large amount ranges from 100 to 200 Yuan; a medium amount from 50 to 100 Yuan; a small amount 0 to 50 Yuan; monthly frequency of various expenses is roughly 1:2:6. To make it convenient for analysis, when interval average is taken from range of expense, spending of a large amount is 150 Yuan; a medium amount is 75 Yuan; a small amount is 25 Yuan. If undergraduates are to maintain monthly financial condition break even, after 600 Yuan of fixed expense required to maintain a daily life is deducted from 1500 Yuan of monthly income, it is feasible to spend a large amount twice, a medium amount 4 times and a small amount 12 times.

\subsection{Analysis results and causes}

The said analysis shows that contemporary Chinese undergraduates' awareness of financial management is still in a developmental stage, their capacity to independently manage personal income and expense is still low, and irrational consumption is common. The reason for this result is attributable to impacts from family environment and social environment Most contemporary Chinese undergraduates were born between 1995 and 2000 when China advocated one-child policy, making most contemporary Chinese undergraduates the only child in their family. Compared with those from family with more than one child, the only child has a higher proportion of household consumption spending. Additionally, over recent years, as economy, especially Internet economy, grows rapidly in China, undergraduates are provided with more accesses to consumption. Online shopping is a major part of consumption patterns of contemporary undergraduates. Online loan has become a significant inducement of undergraduates' overspending.

The questionnaire survey shows over $70 \%$ of undergraduates used Ant Check Later, Campus Loan and other online credit and loan services. Amount of credit and loan varies from 200 to 2000 Yuan. By cross-over analysis, among undergraduates with overspending in living costs, 72.73\% used credit and loan services. Online loan is a double-edged sword. It is easy to operate and it lends borrowings rapidly. However, there is a lack of standardization in online loan platform in China at present. Moreover, interest rate of online loan is usually higher than market interest rate over the same period. Undergraduates have an immature consumer psychology and are apt to meet their large amount consumption needs with online credi and loan. Since undergraduates do not have independent income sources for repayment, their online borrowing will often have negative effects. This is required to be vigilant.

\section{SUGGESTIONS}

In accordance with the preceding data analysis results in this paper, the following suggestions are given of the financial management capability of contemporary undergraduates in China.

Firstly, undergraduates can keep records for daily income and expense, have a clear understanding of their amount of consumption, evaluate rationality of their different consumption behaviors in accordance with those records so as to improve their awareness of financial management. Besides, budge at early month and settlement at late month are also important means for improvement of financial management capacity. In budget at early month, monthly fixed expense should be retained and then predicted amount of variable expense is planned so as to prevent severe consequences of a failure to maintain a daily life due to spending in living costs. An overall amount of budget should be subject to amount of income in living costs. A surplus of 100 to 200 Yuan can be retained in an ideal state so as to deal with spending outside budget. In settlement at late month, overall evaluation should be performed for consumption condition in the current month in accordance with consumption records. Priority is given to analysis for difference between actual spending and budgeted spending. And budget data for next month is adjusted appropriately in accordance with such difference. For undergraduates with severe overspending on a monthly basis, consumption may be further controlled by interim budget and settlement.

Next, in additional to amount of financial income and expense, undergraduates shall also pay attention to rationality of their own consumption mix. Mix of fixed expense keeps unchanged basically while there is a large room for adjustment for mix of variable expense. High attention should be paid to variable expense, which account for $60 \%$ averagely in undergraduates' living costs and a large amount. Undergraduates are supposed to reduce proportion of irrational consumption in variable expense, such as a pure pursuit of brand and appearance. Such consumption behavior will generally give rise to outflow of a large mount and meet undergraduates' irrational consumer psychology. However, value of commodities is generally not in direct proportion to their price. In addition, proportion of rational consumption should be enhanced in variable expense, such as spending for learning materials or sports equipment. Such consumption behavior is highly beneficial to development of undergraduates. In a word, consumption mix is required to be improved by preventing short-term behavior, overcoming irrational consumer psychology of keeping up with the Joneses and following others blindly, and using limited money to items which can bring future earnings to the greatest extent.

Additionally, for undergraduates who always have a surplus in monthly living costs, long-term plan for money is recommended. On the one hand, accumulated surplus money can be used to develop a hobby, such as SLR camera or transport fees for travel. On the other hand, in case of no definite intention of using surplus money, some financial products of a small amount can be purchased as appropriate. During financial products selection, attention shall be paid to risk control and risky speculation prevention. In the process of financial products selection and purchase, undergraduates can not only gain higher income than interest rate of savings, but also cultivate their financial management capacity in a better manner.

In the end, while enhancement of financial management capacity depends heavily on efforts of undergraduates themselves, the supervision and constraint from school and parents are also indispensable. School should carry out relevant public education course appropriately to improve the undergraduates' awareness of financial management. Compared with school, parents are closer to the undergraduates and their responsibilities to supervise undergraduates' consumption behavior are even heavier. Parents can ask their children to inform the general situation of monthly expenses, judge the rationality of their children's monthly consumption expenses and reward or punish them.

\section{SUMMARY}

The financial management capacity of contemporary Chinese undergraduates is not positive in general. The reasons for it are attributable to both social environment and undergraduates themselves. To enhance the financial management capability of college students, not only the Undergraduates are required to make efforts to develop good consumer habits but also the schools and parents need to participate in jointly promote healthy development of undergraduates.

\section{REFERENCES}

[1] Wencheng, M. 2007. Hazards, Causes and Solutions of Financial Distress of Undergraduates. Science and Technology Economy Market, 8 (2), 184-184

[2] Jingmin, Z. 2014. A Study of Undergraduates' View on Money in New Trend of Market Economy. Reading and Calculation, 33 (3), 409-410. 